\title{
PREVALENSI VISUM ET REPERTUM ORANG HIDUP PADA KECELAKAAN LALU LINTAS DI INSTALASI GAWAT DARURAT BLU RSUP PROF. DR. R. D.KANDOU MANADO PERIODE TAHUN 2013
}

\author{
${ }^{1}$ Septyano Sondakh \\ ${ }^{2}$ James F. Siwu \\ ${ }^{2}$ Johannis F. Mallo \\ ${ }^{1}$ Kandidat Skripsi Fakultas Kedokteran Universitas Sam Ratulangi Manado
${ }^{2}$ Bagian Forensik Fakultas Kedokteran Universitas Sam Ratulangi Manado
Email: ssondakh11_219@yahoo.com
}

Abstract: In Prof. Dr. R. D. Kandou Hospital, the incidence of clinical forensic cases of living people mainly caused by traffic accidents increases sharply along with the increasing number of visum et repertum (VeR) requests. This study aimed to determine the prevalence VeR of living people with traffic accidents during 2013. Secondary data were obtained from January to December 2013 at the the emergency unit of Prof. Dr. R. D. Kandou Hospital. This was a descriptive and retrospective study. Data contained the characteristics of patients, including: sex, age, and cause of the accident. The result showed that during the year 2013 the prevalence of living people VeR caused by traffic accidents was the highest in April (11.57\%), dominated by males (80.55\%), the age group of $15-24$ years old (37.79\%), with the cause of accident injured driver due traffic accident (60.54\%).

Keywords: prevalence, living people VeR, traffic accident

\begin{abstract}
Abstrak: Di Badan Layanan Umum (BLU) Rumah sakit Prof. Dr. R. D. Kandou Bagian Instalasi Gawat Darurat (IGD), angka kejadian kasus forensik klinik (Orang hidup) terutama yang disebabkan oleh kecelakaan lalu lintas (KLL) meningkat tajam seiring dengan semakin banyaknya permintaan visum et repertum (VeR). Penelitian ini bertujuan untuk mengetahui angka prevalensi VeR orang hidup yang disebabkan oleh KLL selama tahun 2013 melalui data sekunder di IGD BLU RSUP Prof. Dr. R. D. Kandou, yang dilihat dari karakteristik jenis kelamin, umur, dan jenis penyebab kecelakaan. Penelitian ini bersifat retrospektif deskriptif. Hasil penelitian memperlihatkan bahwa selama tahun 2013 mulai bulan Januari sampai Desember angka prevalensi VeR orang hidup yang disebabkan oleh KLL tertinggi pada bulan April (11,57\%) yang didominasi oleh laki-laki (80,55\%) dengan umur terbanyak pada interval 15-24 tahun (37,79\%) dengan jenis penyebab kecelakaan terbanyak ditemukan driver injured in traffic accident $(60,54 \%)$.
\end{abstract}

Kata kunci: prevalensi, visum et repertum orang hidup, KLL

Di Badan Layanan Umum (BLU) Rumah Sakit Umum Pendidikan (RSUP) Prof. R. D. Kandou bagian Instalasi Gawat Darurat (IGD), angka kejadian kasus forensik klinik (orang hidup) terutama yang disebabkan oleh kecelakaan lalu lintas (KLL) meningkat tajam. KLL sampai saat ini masih merupakan salah satu masalah kesehatan masyarakat di seluruh dunia. Jumlah kasus KLL dari tahun ke tahun terus meningkat. ${ }^{1}$ Menurut data Badan Pusat Statistik Republik Indonesia, pada tahun 2008 jumlah kasus KLL terdapat 59.164 kasus, kemudian meningkat di 
tahun 2009 dengan jumlah 62.960 kasus, dan terus meningkat di tahun 2010 dengan

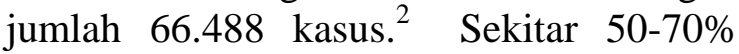
kasus yang datang ke rumah sakit di IGD ialah kasus akibat KLL. ${ }^{3}$ Seiring dengan meningkatnya jumlah kasus KLL yang masuk di IGD BLU RSUP Prof Kandou Manado, maka timbul semakin banyak permintaan Visum et Repertum(VeR).

VeR merupakan alat bukti dalam proses peradilan yang tidak hanya memenuhi standar penulisan rekam medis, tetapi juga harus memenuhi hal-hal yang disyaratkan dalam sistem peradilan. ${ }^{4}$ VeR yang baik harus mampu membuat terang perkara tindak pidana yang terjadi dengan melibatkan bukti-bukti forensik yang cukup. $^{5}$ Seorang dokter yang bertugas di IGD rumah sakit, tugasnya tidak hanya melakukan pemeriksaan medis untuk kepentingan diagnostik dan pengobatan penyakit saja, tetapi juga untuk dibuatkan suatu surat keterangan medis. Demikian pula halnya dengan seorang pasien yang datang ke IGD, tujuan utama ialah untuk mendapatkan pertolongan medis agar penyakitnya sembuh, tetapi bila pasien datang dengan keluhan mengalami KLL, pihak yang berwajib dapat meminta surat keterangan medis atau VeR dari dokter yang memeriksa. Jadi pada satu saat yang sama dokter dapat bertindak sebagai seorang klinisi yang bertugas mengobati penyakit sekaligus sebagai seorang petugas forensik yang bertugas membuat VeR, sedangkan pasien bertindak sebagai seorang yang diobati sekaligus korban yang diperiksa dan hasilnya dijadikan alat bukti. ${ }^{6}$

Dalam hal barang bukti yang terdapat pada korban hidup, maka korban harus dipandang dari dua sisi, yaitu sisi medis dan sisi hukum. Dari sisi medis korban adalah seseorang yang mengalami luka, patah tulang dan lain-lain dengan banyak macam ragam akibat yang terjadi setelah KLL pada korban hidup sehingga perlu untuk ditangani supaya korban dapat sembuh seperti sedia kala, meminimalkan cacat, terutama mencegah kematian. Dari sisi hukum berarti tubuh korban orang hidup merupakan barang bukti. Karena tubuh manusia hidup dapat mengalami perubahan pada tubuh seperti luka-luka, patah tulang, cacat yang dideritanya akibat KLL, maka laporan tertulis tentang keadaan korban dapat dijadikan alat bukti. ${ }^{6}$

Penanganan dan pelaporan yang tepat akan membantu korban untuk mencapai kesembuhan dan mendapat keadilan. Untuk penanganan dan pelaporan maka paling penting juga ialah harus mengetahui identitas korban selain nama, jenis kelamin, umur, penyebab KLL dan lain lain sebagainya. Dalam penelitian ini angka prevalensi kasus VeR orang hidup yang disebabkan oleh KLL dilihat dari karakteristik jenis kelamin, distribusi umur, dan jenis penyebab kecelakaan yang telah terjadi pada tahun 2013.

\section{METODE PENELITIAN}

Jenis penelitian ini retrospektif deskriptif. Penelitian ini dilakukan pada bulan September sampai Desember 2014. Penelitian ini menggunakan data sekunder yaitu data yang diperoleh secara tidak langsung yang berasal dari VeR korban KLL. Populasi ialah VeR korban kasus KLL yang masuk di bagian IGD BLU RSUP Prof. Dr. R. D. Kandou Manado. Sampel penelitian ialah VeR orang hidup kasus KLL yang masuk di bagian IGD BLU RSUP Prof. Dr. R. D. Kandou Manado periode tahun 2013. Kriteria inklusi, yaitu VeR orang hidup pada semua jenis korban KLL. Kriteria eksklusi, yaitu korban yang datanya tidak lengkap dan korban meninggal.

Variabel penelitian yaitu karakteristik korban kecelakaan lalu lintas, jenis kelamin, umur dan jenis kecelakaan lalu lintas. Definisi operasional yaitu karakteristik korban KLL yang dimaksud adalah jenis kelamin dan umur korban sesuai yang tercatat dalam medical record VeR, jenis kelamin adalah dinyatakan dalam laki-laki dan perempuan, umur adalah umur korban kecelakaan lalu lintas orang hidup sesuai dengan yang tercatat dalam medical record VeR. Interval umur dibagi dalam $\leq 4$ tahun, 5-14 tahun, 15-24 tahun, 25-34 tahun, 35-44 tahun, 45-54 
tahun, 55-64 tahun, dan $\geq 65$ tahun, Jenis KLL yang dimaksud adalah jenis kecelakaan yang dialami korban sesuai dengan yang tercatat dalam rekam medik VeR korban kasus KLL orang hidup yang dibagi menjadi unspecified transport accident, driver injured in traffic accident, passenger injured in traffic accident, driver injured in collision with other and unspecified motor vehicles in nontraffic accident, passenger injured in collision with other and unspecified motor vehicles in nontraffic accident, traffic accident. Pengolahan data diolah secara manual dan disajikan dalam bentuk tabel dan gambar.

\section{HASIL PENELITIAN}

Berdasarkan hasil pengumpulan data dari kasus VeR orang hidup korban KLL di bagian IGD BLU RSUP Prof. Dr. R. D. Kandou Manado periode JanuariDesember tahun 2013, yang memenuhi kriteria inklusi dapat dilihat pada gambar dan tabel berikut ini.

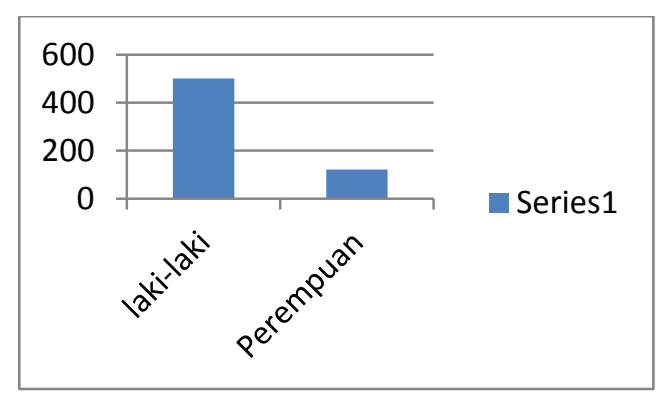

Gambar 1. Distribusi VeR korban KLL orang hidup berdasarkan jenis kelamin tahun 2013

Tabel 1. Distribusi VeR korban kecelakaan lalu lintas orang hidup berdasarkan jenis kelamin

\begin{tabular}{|c|c|c|c|c|c|c|c|c|c|c|c|c|c|}
\hline $\begin{array}{c}\text { Jenis } \\
\text { kelamin } \\
(\%)\end{array}$ & Jan & Feb & Mar & Apr & Mei & Jun & Jul & Agus & Sept & Okt & Nov & Des & $\begin{array}{c}\text { Jumlah } \\
\text { total }\end{array}$ \\
\hline $\begin{array}{c}\text { Laki-laki } \\
(80,55)\end{array}$ & 46 & 29 & 51 & 62 & 37 & 36 & 37 & 34 & 50 & 49 & 29 & 41 & 501 \\
\hline $\begin{array}{c}\text { Perempuan } \\
(19,45)\end{array}$ & 12 & 10 & 11 & 10 & 12 & 7 & 5 & 11 & 9 & 5 & 10 & 19 & 121 \\
\hline $\begin{array}{c}\text { Total } \\
(100)\end{array}$ & 58 & 39 & 62 & 72 & 49 & 43 & 42 & 45 & 50 & 54 & 39 & 60 & 622 \\
\hline
\end{tabular}

Tabel 2. Distribusi VeR KLL orang hidup berdasarkan umur

\begin{tabular}{|c|c|c|c|c|c|c|c|c|c|c|c|c|c|}
\hline $\begin{array}{c}\text { Interval } \\
\text { umur } \\
\text { dalam } \\
\text { thn } \\
(\%)\end{array}$ & Jan & Feb & Mar & Apr & Mei & Jun & Jul & Agus & Sept & Okt & Nov & Des & Jumlah \\
\hline $\begin{array}{c}\leq 4 \\
(0,48)\end{array}$ & 0 & 0 & 0 & 0 & 1 & 0 & 0 & 1 & 1 & 0 & 0 & 0 & 3 \\
\hline $\begin{array}{c}5-14 \\
(11,25)\end{array}$ & 8 & 5 & 8 & 7 & 7 & 3 & 3 & 4 & 5 & 4 & 7 & 9 & 70 \\
\hline $\begin{array}{c}15-24 \\
(37,79) \\
\end{array}$ & 12 & 15 & 27 & 24 & 20 & 188 & 20 & 20 & 22 & 21 & 13 & 23 & 235 \\
\hline $\begin{array}{c}25-34 \\
(19,45) \\
\end{array}$ & 13 & 9 & 8 & 11 & 8 & 6 & 10 & 5 & 12 & 12 & 15 & 12 & 121 \\
\hline $\begin{array}{c}35-44 \\
(19,45)\end{array}$ & 6 & 10 & 7 & 10 & 5 & 9 & 8 & 6 & 9 & 3 & 3 & 5 & 81 \\
\hline $\begin{array}{l}45-54 \\
(8,69) \\
\end{array}$ & 9 & 0 & 3 & 9 & 5 & 4 & 5 & 4 & 3 & 5 & 6 & 1 & 54 \\
\hline $\begin{array}{l}55-64 \\
(5,79)\end{array}$ & 5 & 0 & 3 & 6 & 3 & 1 & 2 & 4 & 3 & 1 & 4 & 4 & 36 \\
\hline $\begin{array}{c}\geq 65 \\
(3,53)\end{array}$ & 3 & 3 & 2 & 1 & 2 & 2 & 1 & 1 & 2 & 1 & 3 & 1 & 22 \\
\hline $100 \%$ & 56 & 42 & 58 & 68 & 51 & 43 & 49 & 45 & 57 & 47 & 51 & 55 & 622 \\
\hline
\end{tabular}




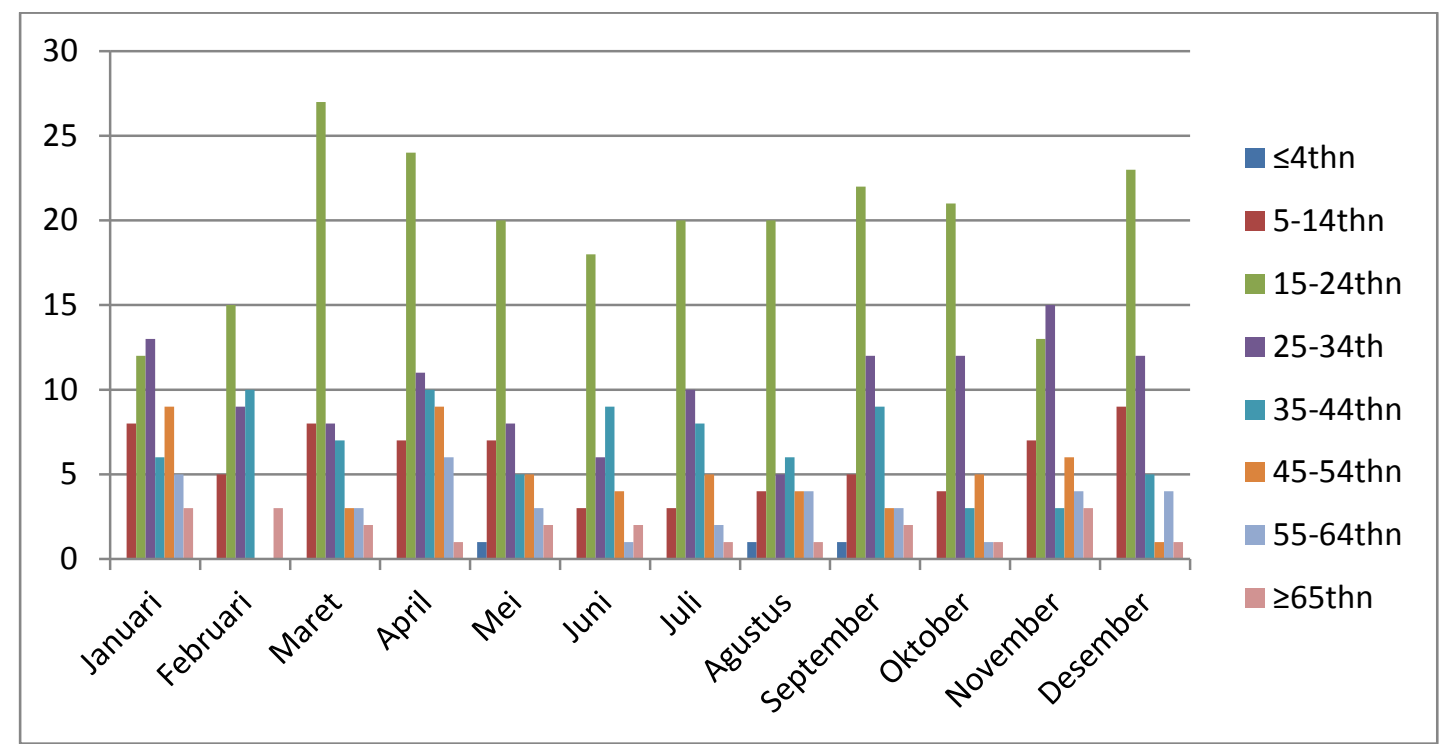

Gambar 2. Distribusi VeR korban KLL orang hidup berdasarkan umur tahun 2013

Tabel 3. Distribusi VER KLL orang hidup berdasarkan jenis kecelakaan

\begin{tabular}{|c|c|c|c|c|c|c|c|c|c|c|c|c|c|}
\hline $\begin{array}{c}\text { Jenis } \\
\text { kecelakaan } \\
(\%)\end{array}$ & Jan & Feb & Mar & Apr & Mei & Jun & Jul & Agus & Sept & Okt & Nov & Des & $\begin{array}{c}\text { Jumlah } \\
\text { total }\end{array}$ \\
\hline $\begin{array}{c}\text { Unspecified } \\
\text { transport } \\
\text { accident } \\
(2,74)\end{array}$ & 3 & 1 & 0 & 2 & 0 & 1 & 0 & 3 & 1 & 0 & 1 & 1 & 13 \\
\hline $\begin{array}{l}\text { Driver } \\
\text { injured in } \\
\text { traffic } \\
\text { accident } \\
(60,54)\end{array}$ & 3 & 3 & 26 & 31 & 18 & 26 & 27 & 25 & 41 & 43 & 20 & 24 & 287 \\
\hline $\begin{array}{l}\text { Passenger } \\
\text { injured in } \\
\text { traffic } \\
\text { accident } \\
(16,45)\end{array}$ & 2 & 0 & 6 & 4 & 7 & 4 & 10 & 7 & 11 & 5 & 8 & 14 & 78 \\
\hline $\begin{array}{c}\text { Driver } \\
\text { injured in } \\
\text { collision } \\
\text { with other } \\
(7,17)\end{array}$ & 0 & 3 & 3 & 4 & 6 & 2 & 0 & 2 & 2 & 1 & 4 & 7 & 34 \\
\hline $\begin{array}{l}\text { Passenger } \\
\text { injured in } \\
\text { collision } \\
\text { with other } \\
\text { and } \\
\text { unspecified } \\
\text { motor } \\
\text { vehicles in } \\
\text { non-traffic } \\
\text { accident } \\
(1,47)\end{array}$ & 0 & 1 & 0 & 0 & 1 & 0 & 0 & 0 & 2 & 1 & 0 & 2 & 7 \\
\hline $\begin{array}{c}\text { Traffic } \\
\text { accident } \\
(11,60) \\
\end{array}$ & 0 & 0 & 5 & 6 & 7 & 4 & 3 & 8 & 2 & 3 & 6 & 11 & 55 \\
\hline Total $100 \%$ & 8 & 8 & 40 & 47 & 39 & 37 & 40 & 45 & 59 & 53 & 39 & 59 & 474 \\
\hline
\end{tabular}




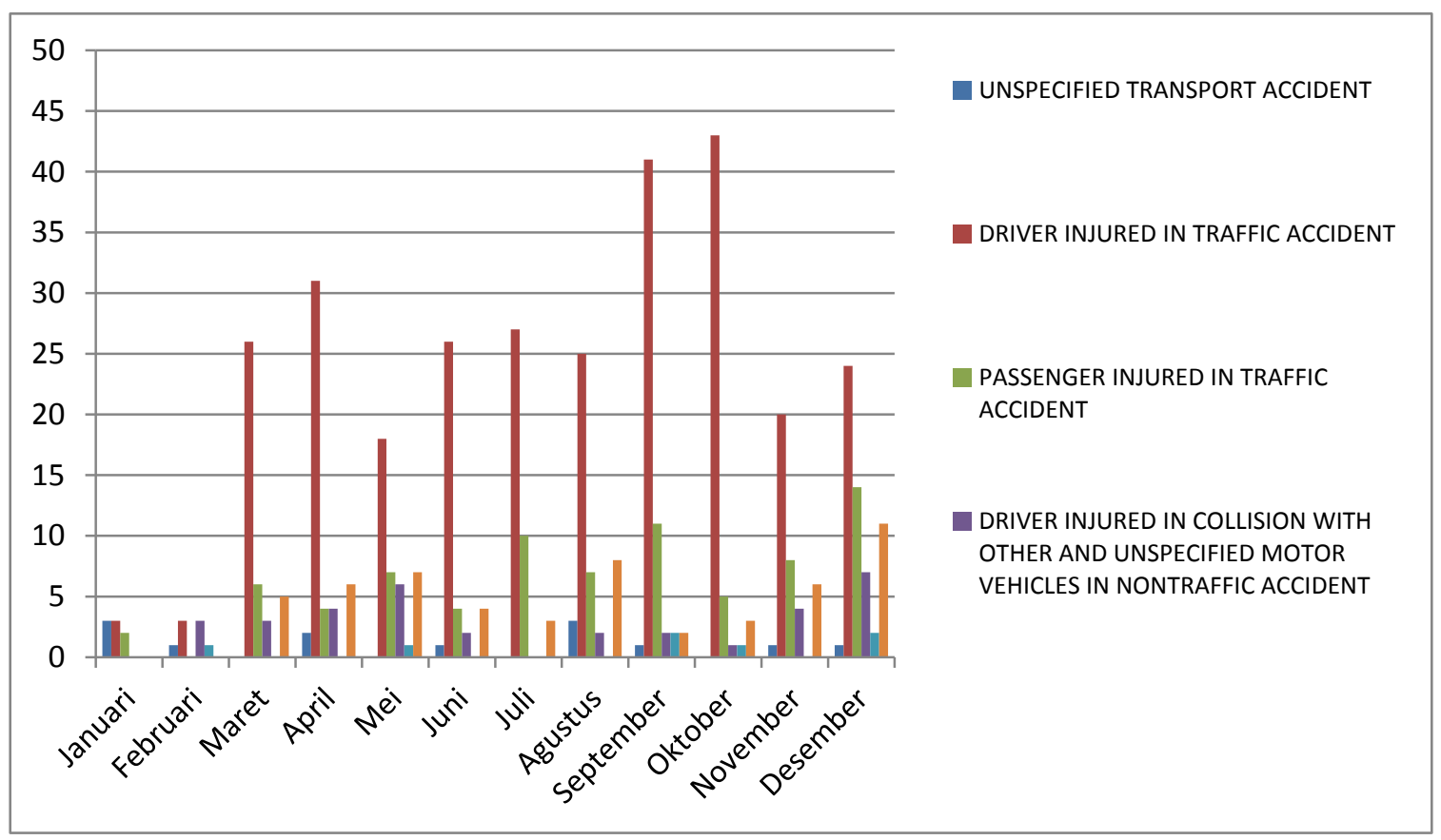

Gambar 3. Distribusi VeR korban KLL orang hidup berdasarkan jenis kecelakaan 2013

\section{BAHASAN}

Hasil penelitian retrospektif deskriptif korban kasus KLL orang hidup di IGD BLU RSUP Prof. Dr. R. D. Kandou Manado periode Januari- Desember tahun 2013 memperlihatkan jumlah keseluruhan korban kasus yang sesuai kriteria inklusi sebanyak 622 orang. Angka prevalensi VeR orang hidup di IGD BLU RSUP Prof. Dr. R. D. Kandou bervariasi dilihat dari segi karakteristik jenis kelamin, umur dan jenis kecelakaan.

Tabel 1 dan Gambar 1 menunjukkan VeR KLL orang hidup berdasarkan jenis kelamin tertinggi pada bulan April (11,57\%), dan didominasi oleh jenis kelamin laki-laki (80,55\%). Hasil penelitian ini serupa dengan penelitian Kartika M. 2008. ${ }^{7}$ Hal ini kemungkinan disebabkan karena laki-laki lebih sering mengemudikan kendaraan dengan kecepatan tinggi dibandingkan perempuan sehigga berisiko lebih tinggi mengalami kecelakaan. $^{7,8}$

Tabel 2 dan Gambar 2 menunjukkan bahwa interval umur 15-24 tahun (37,79\%) merupakan persentase tertinggi oleh karena kelompok umur ini merupakan usia produktif dan mempunyai mobilitas yang lebih tinggi dibandingkan dengan kelompok umur yang lain. Hasil penelitian ini sama dengan penelitian pola luka yang diteliti oleh Angela et al. ${ }^{8}$

Tabel 3 dan Gambar 3 menunjukkan jenis penyebab kecelakaan terbanyak ialah driver injured in traffic accident (60,54\%). Hal ini bisa terjadi antara lain akibat pengemudi roda dua tidak memakai helm berstandar pada pengemudi bermotor atau pengemudi roda empat tidak memakai sabuk pengaman, tidak mematuhi ramburambu lalu lintas, ugal-ugalan, menggunakan ponsel saat berkendara, mengantuk, minum minuman keras, dll.

\section{SIMPULAN}

Berdasarkan hasil penelitian maka dapat disimpulkan bahwa angka prevalensi VeR KLL orang hidup di bagian IGD BLU RSUP Prof. Dr. R. D. Kandou Manado periode Januari- Desember tahun 2013 tertinggi pada laki-laki, interval umur 1524 tahun, dan jenis penyebab kecelakaan terbanyak ditemukan driver injured in traffic accident. 


\section{SARAN}

Mengingat pentingnya VeR orang hidup korban kasus KLL maka rekam medik pasien harus lengkap.

\section{DAFTAR PUSTAKA}

1. World Health Organization (WHO). Traffic Accidents. [cited 2008 Jun 2]. Available from: http:// www.who.int/ world-health-day/ previous/ 2004/ infomaterials/ world_report/ en/. [Last update: Januari 2007].

2. BPS. Statistik jumlah kecelakaan lalu lintas. Badan Pusat Statistik, Republik Indonesia 1992-2010.

3. Atmadja DS. Simposium tatalaksana VeR korban hidup pada kasus perlukaan dan keracunan di Rumah Sakit. Jakarta: RS Mitra Keluarga Kelapa Gading, Rabu 23 Juni 2004.

4. Herkutanto. Peningkatan kualitas pembuatan visum et repertum (VER) kecederaan di rumah sakit melalui pelatihan dokter unit gawat darurat (UGD). JPMK. 2005;8(3):163-9.

5. Afandi D. Visum et Repertum of Injury: Medicolegal aspect and determining degree of injury. Maj. Kedokt Indon. 2010;60(4).

6. Bagian Ilmu Kedokteran Forensik dan Medikolegal Fakultas Kedokteran Indonesia. Pedoman teknik pemeriksaan dan interpretasi luka dengan orientasi medikolegal atas kecederaan. Jakarta, 2005.

7. Kartika M. Analisis faktor penyebab kecelakaan lalu lintas pada pengendara sepeda motor di wilayah Depok [Skripsi]. Jakarta: Fakultas Kesehatan Masyarakat Universitas Indonesia, 2008.

8. Angela Z, Tomuka D. Ch, Siwu J. Pola luka pada kasus kecelakaan lalu lintas di BLU RSU Prof. Dr. R. D. Kandou Manado periode 2010-2011. Jurnal eBiomedik (eBM). 2013;1(1):683. 